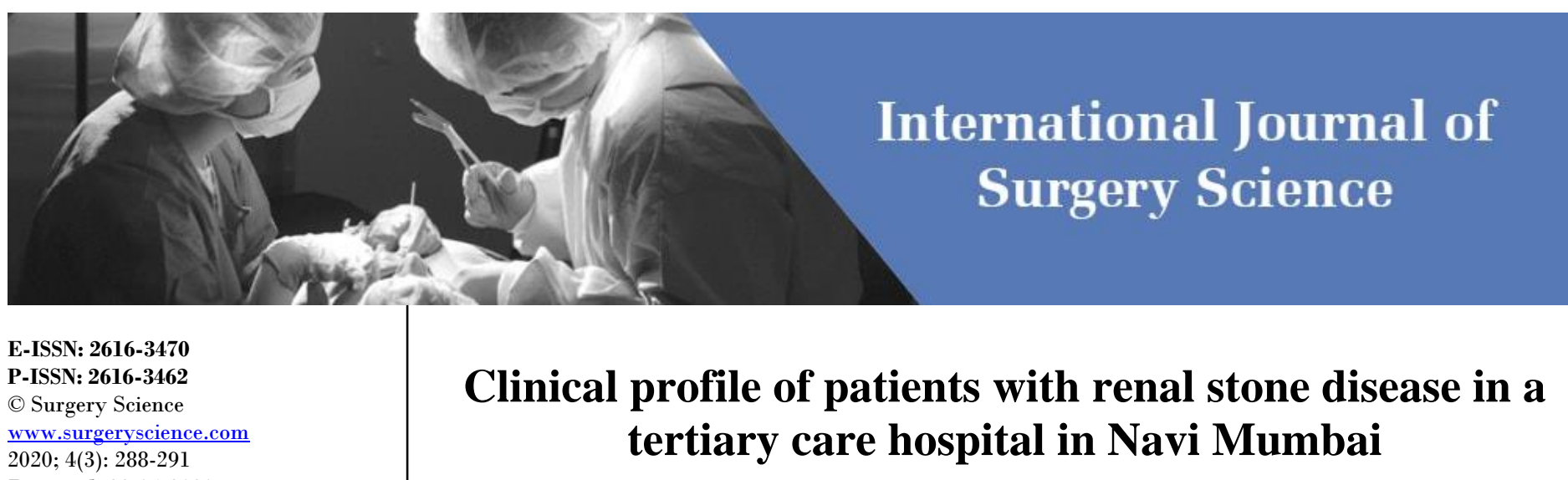

Received: 22-05-2020

Accepted: 24-06-2020

Anuradha Panchal

Department of General Surgery,

Dr. D.Y. Patil Medical College and

Hospital, Nerul, Navi Mumbai,

Maharashtra, India

\section{Raj Gautam}

Department of General Surgery,

Dr. D.Y. Patil Medical College and

Hospital, Nerul, Navi Mumbai,

Maharashtra, India

\section{Aniket Ray}

Department of General Surgery, Dr. D.Y. Patil Medical College and Hospital, Nerul, Navi Mumbai,

Maharashtra, India

\section{Pranav Narayan}

Department of General Surgery,

Dr. D.Y. Patil Medical College and

Hospital, Nerul, Navi Mumbai,

Maharashtra, India

\section{Rohith Pillai}

Department of General Surgery,

Dr. D.Y. Patil Medical College and

Hospital, Nerul, Navi Mumbai,

Maharashtra, India

\section{Mukul Mapari}

Department of General Surgery, Dr. D.Y. Patil Medical College and Hospital, Nerul, Navi Mumbai,

Maharashtra, India
Corresponding Author:

Aniket Ray

Department of General Surgery,

Dr. D.Y. Patil Medical College and

Hospital, Nerul, Navi Mumbai,

Maharashtra, India

\author{
Anuradha Panchal, Raj Gautam, Aniket Ray, Pranav Narayan, Rohith \\ Pillai and Mukul Mapari
}

DOI: https://doi.org/10.33545/surgery.2020.v4.i3e.510

\begin{abstract}
Renal stones is a common condition affecting human beings of both genders and all age groups worldwide. Their presentation vary from unilateral loin region pain to nausea vomiting, to burning micturation or even haematuria. Patient profile of renal stone disease differs from one geographical region to another Therefore this prospective observational study was conducted in Dr. D.Y. Patil Medical College and Hospital, Nerul, Navi Mumbai to find out patient characteristics of this region. 100 patients were included in the study. $82 \%$ patients were females most of whom were housewives. $48 \%$ patients belonged to the age group 41-60 years. Most common presentation was left sided flank pain. CT scan and USG abdomen were equally accurate in determining the size of the renal stone. Most of the females were managed conservatively whereas most males required intervention like URS or PCNL for their treatment.
\end{abstract}

Keywords: Ureterorenoscopy (URS), percutaneous nephrolithotripsy (PCNL), staghorn calculus, calcium oxalate monohydrate, calcium oxalate dehydrate

\section{Introduction}

Kidney stone disease is a very common and painful condition and has been reported since ancient times. 1 The stone formed in this condition can cause renal colic which many patients have described as the worst pain they have experienced.2 A very common issue with all types of stone disease is their tendency to recur; and preventing recurrence is an important part of the treatment.1 Stone disease is a significant economic burden on the patients due to the recurring nature of the disease; ${ }^{[3]}$ with a sizeable chunk of the economic burden attributable to the expenditure towards surgical treatment of the disease.

Kidney stone is one of the most prevalent disorders affecting the urinary tract ${ }^{[1]}$. Its global prevalence estimate ranges between 2 to $20 \%{ }^{[3]}$. The prevalence of stone disease varies depending on the age, sex, and race ${ }^{[2]}$. It is more commonly reported between the ages of 30 and 60 years. It is more commonly seen in males ${ }^{[1]}$. The prevalence in Europe ranges between 2 to $8 \%$ and between 7 to $12 \%$ in the USA. It has also been reported that men from United Arab Emirates and Saudi Arabia have the highest lifetime risk of stone formation.3 An estimated 12\% of Indians will develop urinary stones at some point of which kidneys loss or renal damage may occur in 50\% patients. Around 10-20\% of males and 3-5\% of females report renal colic (i.e. severe pain due to kidney stone) ${ }^{[1]}$. Recurrence of this disease is also very high with an estimated $50 \%$ of stone patients who underwent treatment initially showing recurrence within 10 years ${ }^{[3]}$. Evidence seems to support a growing incidence of stone disease worldwide which has been attributed to the increasing influence of western lifestyle (e.g., dietary changes, increasing body mass index) ${ }^{[2]}$.

Studies have shown a positive correlation between the temperature and prevalence of kidney stones ${ }^{[4]}$. A study by Brikowski et al found that increased mean temperatures predicted in the future due to global warming is likely to increase the prevalence of kidney stones with a projected increase of as much as 30\% in some areas of USA.5 Stone formation has also been found to be associated with dehydration especially in warm climates. All of this suggests that the prevalence of stone disease is likely to increase in the future.

The stones are formed as solid crystals crystallizing out of dissolved minerals from the urine, and may be triggered by either environmental or metabolic factors. 
Urinary stones tend to be heterogeneous in composition with an estimated $80-90 \%$ of stones being made of calcium salts.

Almost $70 \%$ of renal stones described in developed countries are formed from calcium oxalate and/or phosphate stones. 1 The other materials forming stones are uric acid, struvite, and cystine. In very rare circumstances the stone may be made of medications such as acyclovir, indinavir, and triamterene. However the stone may be made up of more than one type of material, with small proportion of proteins stuck in some of the stones as well ${ }^{[2]}$.

In a study by Ansari et al in India to study the nature of the stones found that about $93 \%$ were made of calcium oxalate of which $80 \%$ were calcium oxalate monohydrate (COM) and $20 \%$ were calcium oxalate dihydrate (COD). $1.4 \%$ was made of struvite, $1.8 \%$ of apatite, $0.9 \%$ was uric acid stones and the remaining $2.8 \%$ were mixed stones. $89.98 \%$ of staghorn stones were oxalates (COM/+COD) and $4.02 \%$ were struvite. In India it has been consistently reported that the prevalence of oxalate stones i.e. COM/COD is considerably higher than their prevalence in other parts of the world ${ }^{[6]}$.

The renal stone disease is a very prevalent condition and some studies suggest that the prevalence is likely to increase further due to dietary changes and global warming. It is a condition with great risk of morbidity and causes immense discomfort to the patients especially in cases of renal colic. The treatment of choice depends of the kind of stone involved; hence it is important that data be generated from an Indian perspective about the surgeries carried out and their associated complications. This study aims to find out the clinical profile of patients with renal stone disease in the geographical location of Navi Mumbai, and treatment they underwent.

\section{Material and Methods}

It is a prospective observational study conducted in Department of General Surgery in Dr. D.Y. Patil Medical College and hospital, Nerul, Navi Mumbai. Study was conducted over the period of one year and the first 100 patients were included in the study. Therefore random sampling method was used.

\section{Inclusion criteria}

1. all patients with renal stones above the age of 14 years.

2. patients not having other diseases of the kidney.

\section{Exclusion criteria}

1. pediatric age group (below 14 years).

2. patients with other diseases of kidney apart from renal calculi.

\section{Results}

In the present study, a total of 100 patients were assessed.

\section{Age distribution}

Table 1: Age distribution

\begin{tabular}{|c|c|c|}
\hline $\begin{array}{c}\text { Age group } \\
\text { (years) }\end{array}$ & $\begin{array}{c}\text { No. of patients } \\
(\mathbf{N})\end{array}$ & $\begin{array}{c}\text { Percentage of patients } \\
(\%)\end{array}$ \\
\hline$\leq 20$ & 2 & 2.00 \\
\hline $21-40$ & 42 & 42.00 \\
\hline $41-60$ & 48 & 48.00 \\
\hline$>61$ & 8 & 8.00 \\
\hline Total & 100 & 100.00 \\
\hline
\end{tabular}

Of the total 100 patients enrolled, 48 (48\%) belonged to the age group of $41-60$ years, $42(42 \%)$ were between $21-40$ years of age, $8(8 \%)$ patients were aged more than 61 years while only 2 $(2 \%)$ patients was $\leq 20$ years.

\section{Gender distribution}

Table 2: Gender distribution

\begin{tabular}{|c|c|c|c|}
\hline Gender & $\mathbf{N}$ & $\mathbf{\%}$ & P value* \\
\hline Males & 18 & 18.00 & $<0.0001$ \\
\hline Females & 82 & 82.00 & \\
\hline Total & 100 & 100.00 & \\
\hline *Calculated using Sign and Binomial Test. P value $<0.05$ is \\
considered significant.
\end{tabular}

Out of the 100 patients, $82(82 \%)$ were females, while $18(18 \%)$ were males. Using the Sign and Binomial test, a p-value of $<0.0001$ was obtained, indicating a significant difference among the distribution of gender.

\section{Occupation}

Table 3: Occupation

\begin{tabular}{|c|c|c|}
\hline Occupation & $\mathbf{N}$ & \% \\
\hline Housewife & 56 & 56.00 \\
\hline Teacher & 2 & 2.00 \\
\hline Student & 12 & 12.00 \\
\hline Sweeper & 2 & 2.00 \\
\hline Fruit vendor & 2 & 2.00 \\
\hline Business & 8 & 8.00 \\
\hline Clerk & 6 & 6.00 \\
\hline Cook & 4 & 4.00 \\
\hline Farmer & 2 & 2.00 \\
\hline Manager & 2 & 2.00 \\
\hline Accountant & 2 & 2.00 \\
\hline Nurse & 2 & 2.00 \\
\hline Total & 100 & 100.00 \\
\hline
\end{tabular}

In our study, the distribution of occupation among our study population was as follows: majority $56(56 \%)$ were housewives, $12(12 \%)$ were students, $8(8 \%)$ had their own business, $6(6 \%)$ were clerks, $4(4 \%)$ were cooks, and $2(2 \%)$ patients each were teacher, sweeper, fruit vendor, farmer, manager, accountant and nurse.

\section{Past History/ Co Morbidities}

Table 4: Past History

\begin{tabular}{|c|c|c|}
\hline Patient History & $\mathbf{N}$ & $\mathbf{\%}$ \\
\hline Diabetes Mellitus & 10 & 10.00 \\
\hline Hypertension & 4 & 4.00 \\
\hline Tuberculosis & 6 & 6.00 \\
\hline No past history & 78 & 78.00 \\
\hline Renal colic & 2 & 2.00 \\
\hline Total & 100 & 100.00 \\
\hline
\end{tabular}

In the present study, most patients $78(78 \%)$ had no past history, while $10(10 \%)$ patients had diabetes mellitus, $6(6 \%)$ had tuberculosis, $4(4 \%)$ had hypertension and $2(2 \%)$ patients had a history of renal colic. 


\section{Addiction}

Table 5: Addiction

\begin{tabular}{|c|c|c|c|}
\hline Addiction & $\mathrm{N}$ & $\%$ & P-value* \\
\hline Alcohol & 6 & 6.00 & \multirow{6}{*}{0.002} \\
\hline Tobacco & 2 & 2.00 & \\
\hline Gutkha & 4 & 4.00 & \\
\hline Cigarette & 10 & 10.00 & \\
\hline IB & 2 & 2.00 & \\
\hline No addiction & 76 & 76.00 & \\
\hline Total & 100 & 100 & \\
\hline
\end{tabular}

While most $76(76 \%)$ of our study patients had no addiction, addictions were noted for cigarette [10 (10\%)], alcohol [6 (6\%)], gutkha [4 (4\%)] and tobacco and IB [2 (2\%)]. A significant difference ( $\mathrm{p}$ 0.002) was observed among our study patients, with a greater proportion of patients having no addiction.

\section{Chief Complaints}

Table 6: Chief complaints

\begin{tabular}{|c|c|c|}
\hline Chief complaints & N & \% \\
\hline Left Flank pain & 34 & 34.00 \\
\hline Bilateral Flank pain & 24 & 24.00 \\
\hline Right Flank pain & 32 & 32.00 \\
\hline Burning Micturition & 10 & 10.00 \\
\hline Total & 100 & 100.00 \\
\hline
\end{tabular}

Of the total 100 patients, $34(34 \%)$ had left flank pain, $32(32 \%)$ had right flank pain, 24 (24\%) had bilateral flank pain and 10 (10\%) had complaints of burning micturition.

\section{Per Abdomen}

Table 7: Per abdomen Systematic Examination

\begin{tabular}{|c|c|c|}
\hline Findings & N & \% \\
\hline Left renal angle tenderness & 32 & 32.00 \\
\hline Right renal angle tenderness & 26 & 26.00 \\
\hline No tenderness & 42 & 42.00 \\
\hline Total & 100 & 100.00 \\
\hline
\end{tabular}

Systemic examination of the abdomen revealed no tenderness in $42(42 \%)$ patients, left renal angle tenderness in $32(32 \%)$ patients and right renal angle tenderness in $26(26 \%)$ patients.

\section{Serum Creatinine}

Table 8: Creatinine

\begin{tabular}{|c|c|c|c|}
\hline Creatinine & Males & Females & P-value* \\
\hline Mean & 0.93 & 1.05 & \multirow[b]{2}{*}{0.5292} \\
\hline SD & 0.39 & 0.50 & \\
\hline *Calculated & $\begin{array}{r}\text { paired } \\
\text { sig }\end{array}$ & $\begin{array}{l}\text { P value } \\
\text { nt. }\end{array}$ & onsidered \\
\hline
\end{tabular}

In our study, the mean \pm SD creatinine level in males was $0.93 \pm$ $0.39 \mathrm{mg} / \mathrm{dL}$ and $1.05 \pm 0.50 \mathrm{mg} / \mathrm{dL}$ in females. Using the unpaired t-test, a p value of 0.5292 was obtained, which indicated no significant difference in the creatinine levels between males and females.

\section{Radiological investigations}

Table 9: Radiological investigation findings

\begin{tabular}{|c|c|c|c|}
\hline Radiological investigation & Mean size & SD & P-value* \\
\hline USG & 7.04 & 2.11 & \\
\cline { 1 - 3 } CT & 7.04 & 2.11 & 0.5 \\
\hline *Calculated using Unpaired t-test. P value <0.05 is considered \\
significant. \\
\hline
\end{tabular}

Of the radiological investigations performed in our study, the mean \pm SD size of renal stone observed was same $(7.04 \pm 2.11$ $\mathrm{mm}$ ) via ultrasonography (USG) as well as computed tomography (CT). The unpaired t-test revealed a p-value of 0.5 . Since the p- value was $<0.05$, there was no significant difference between the two radiological investigations.

\section{Procedures performed}

Table 10: Surgical management

\begin{tabular}{|c|c|c|c|c|c|}
\hline \multirow{2}{*}{ Type of management } & \multicolumn{2}{|c|}{ Males } & \multicolumn{2}{c|}{ Females } & \multirow{2}{*}{ P value* } \\
\cline { 2 - 5 } & $\mathbf{N}$ & $\mathbf{\%}$ & $\mathbf{N}$ & $\mathbf{\%}$ & \\
\hline PCNL & 4 & 22.22 & 16 & 19.51 & \\
\hline URS & 10 & 55.56 & 22 & 26.83 & \multirow{2}{*}{0.2809} \\
\hline Cystolithotripsy & 0 & 0 & 12 & 14.63 & \\
\hline $\begin{array}{l}\text { Conservative } \\
\text { management }\end{array}$ & 4 & 22.22 & 32 & 39.02 & \\
\hline \multicolumn{7}{|c|}{ Total } & 18 & 100 & 82 & 100 & \\
\hline *Calculated using Chi-square test. P value <0.05 is considered \\
significant. \\
\hline
\end{tabular}

In our study, PCNL was performed in 4/18 (22.22\%) males and $16 / 82(19.51 \%)$ females; URS was done in $10 / 18(55.56 \%)$ males and 22/82 (26.83\%) females; cystolithotripsy was performed in $12 / 82(14.63 \%)$ females; while $4 / 18(22.22 \%)$ males and $32 / 82(39.02 \%)$ females were conservatively managed. The chi-square test revealed a p- value of 0.2809 , indicating no significant difference between the types of management among the two genders.

\section{Discussion}

Renal stone disease is a very prevalent condition that is likely to increase further on account of the growing dietary changes and global warming. It has a great risk of morbidity and causes immense discomfort to patients. The treatment of choice depends of the kind of stone involved; hence it is important that data be generated from an Indian perspective about the patient profile with renal stone disease and procedures carried out for their treatment.

In our study, majority of patients $(48 \%)$ belonged to the age group of 41-60 years followed by 21-40 years of age (42\%) and while $8 \%$ patients were above 61 years of age. Least patients were observed in age group of less than 20 which comprised of only $2 \%$ patients. Patel PB et al, from their study findings found that maximum people develop kidney stone in the age group 20 to 40 years $(51 \%) .7$ A similar study by Gillen et al. found the mean age of their patients as $54.1 \pm 0.7$ years. 8

It was observed in our study that majority of the patients were females $(82 \%)$; whereas contradictory findings were seen by Patel PB et al where a very high percentage of males with renal calculi $(89 \%)$ compared to females $(11 \%)$.

In our study, out of the total patients admitted, $56 \%$ were housewives followed by students (12\%), businessmen $(8 \%)$ and clerks (6\%). Patel PB et al observed that the hard working population such as daily wagers and farmers were the major 
groups which developed kidney stones (49\%) than service class people $(25 \%)$ and then students and housewives (22\%). People living luxurious lives like business-class people were observed to have the least risk of renal calculi formation (4\%).7

It was observed in our study that $78 \%$ of the patients did not have any history of illness. $10 \%$ of the patients had history of Diabetes mellitus, followed by $6 \%$ of the patients having Tuberculosis. A different range of pre-existing diseases were noted by Patel et al (Figure 6.1).

In our present study, $82 \%$ patients had no family history of renal stones while $8 \%$ had a family history of tuberculosis and $6 \%$ had Diabetes mellitus.

In our study, 34\% patients suffered from left flank pain $24 \%$ had right flank pain while bilateral flank pain was noted in $24 \%$ patients and $10 \%$ had burning micturition.

In our study, majority of the patients had no addiction $(76 \%)$, whereas addiction was seen for cigarette (10\%) and alcohol $(6 \%)$.

On systemic examination of abdomen of the patients in our study, it was reported that $32 \%$ of the patients developed left renal angle tenderness and $26 \%$ of the patients developed right renal angle tenderness. No abnormal deformity was seen in $42 \%$ of the patients.

Serum creatinine level is increased in chronic renal failure patients as creatinine clearance is affected. The mean \pm SD creatinine levels in our study were reported to be $0.93 \pm 0.39$ in males and $1.05 \pm 0.50$ in females. Suresh $M$ et al. reported that the creatinine count in his study was $4.76 \pm 2.29 \mathrm{mg} / \mathrm{dL}$. ${ }^{\text {[9] }}$

In our study, radiological investigations performed revealed a mean size of renal stones as $7.04 \pm 2.11 \mathrm{~mm}$ using USG and as well as by CT. In a study conducted by Mitterberger $M$ et al. 77 urinary stones had a mean size of $5 \pm 0.3 \mathrm{~mm}$ on unenhanced CT; whereas the mean size of 51 urinary stones detected on USG was $7 \pm 0.5 \mathrm{~mm} .10$

It was observed in our study that majority of the males underwent URS $(55.56 \%)$ followed by PCNL and conservative management $(22.22 \%$ each) when it came to surgical management of the renal stones; whereas in females, majority underwent conservative management $(39.02 \%)$, followed by URS (26.83\%), PCNL (19.51\%) and cystolithotripsy (14.63\%).

\section{Conclusion}

1. Majority of the patients were observed to be in the age group of 41-60 constituting of $48 \%$ of the sample size followed by the age group of $21-40$ having $42 \%$ of the population.

2. $82 \%$ of the sample size constituted of females and males constituted of $18 \%$.

3. Among the sample size, housewives were in majority i.e., $56 \%$ followed by students at $12 \%$ and business people at $8 \%$.

4. $78 \%$ of the patients had no past history of any diseases followed by patients having a history of diabetes mellitus $(10 \%)$ and tuberculosis (6\%).

5. Left flank pain was the most common complaint in $34 \%$ of the patients followed by right flank pain in $32 \%$ of the patients and bilateral flank pain in $24 \%$ of the patients.

6. It was observed that $76 \%$ of the patients had no addiction to anything followed by $10 \%$ of the patients addicted to cigarette and $6 \%$ addicted to alcohol.

7. On examination of the abdomen, no abnormal deformity was observed in $42 \%$ of the patients followed by left renal angle tenderness in $32 \%$ of the patients and right angle tenderness in $26 \%$ of the patients.
8. Creatinine values were observed to be $0.93 \pm 0.39$ in males and $1.05 \pm 0.50$ in females.

9. On radiological investigations using USG and CT, the size of the renal stone was found to be $7.04 \pm 2.11 \mathrm{~mm}$ in both USG as well as CT respectively.

10. $55.56 \%$ of the males underwent URS which was followed by PCNL and conservative management (22\% each) when it came to treatment of renal stones using surgery. In case of females, $39.02 \%$ underwent conservative management followed by URS (26.83\%) and PCNL (19.51\%).

\section{References}

1. Sofia NH, Manickavasakam K, Walter TM. Prevalence and Risk Factors of Kidney Stone. Global Journal for Research Analysis. 2016; 5(3):183-187.

2. Jameson JN, Kasper DL, Harrison TR, Braunwald E, Fauci AS, Hauser SL et al. Harrison's principles of internal medicine. 18th ed. New York: McGraw-Hill Medical Publishing Division, 2012.

3. Johri N, Cooper B, Robertson W, Choong S, Rickards D, Unwin R. An Update and Practical Guide to Renal Stone Management. Nephron Clinical Practice. 2010; 116(3):c159-71.

4. Romero V, Akpinar H, Assimos DG. Kidney stones: a global picture of prevalence, incidence, and associated risk factors. Rev Urol. 2010; 12(2, 3):e86-96.

5. Brikowski TH, Lotan Y, Pearle MS. "Climate-Related Increase in The Prevalence Of Urolithiasis In The United States". Proceedings of the National Academy of Sciences 2008; 105(28):9841-6.

6. Ansari M, Gupta N, Hemal A, Dogra P, Seth A, Aron M et al. Spectrum of stone composition: structural analysis of 1050 upper urinary tract calculi from northern India. International Journal of Urology. 2005; 12(1):12-16.

7. Patel PB. Analysis of Kidney Stones Prevalent in Saurashtra Region (Doctoral dissertation, Saurashtra University).

8. Gillen DL, Coe FL, Worcester EM. Nephrolithiasis and increased blood pressure among females with high body mass index. American journal of kidney diseases. 2005; 46(2):263-9.

9. Suresh M, Reddy MN. Hematological Changes In Chronic Renal Failure. International Journal of Scientific and Research Publication. 2012; 9(2):1-4. Print.

10. Mitterberger M, Aigner F, Pallwein L, Pinggera GM, Neururer R, Rehder P et al. Sonographic detection of renal and ureteral stones: value of the twinkling sign. International braz j urol. 2009; 35(5):532-41 